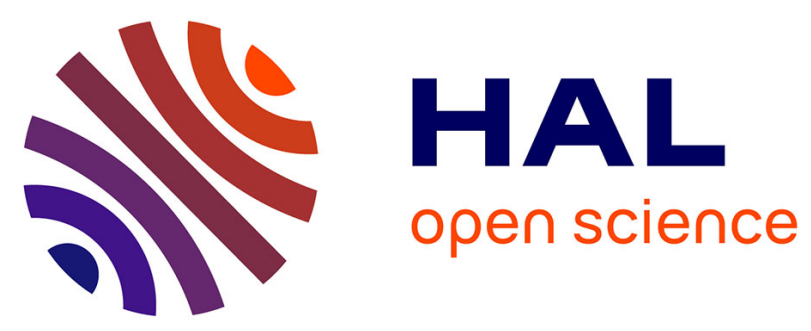

\title{
Indentation-induced stress distribution and pressure effect on the resistivity of YSZ
}

Yusuke Daiko, Eri Takahashi, Yann Gueguen, Hiroyuki Muto, Atsunori Matsuda, Tetsuo Yazawa, Tanguy Rouxel, Yuji Iwamoto

\section{To cite this version:}

Yusuke Daiko, Eri Takahashi, Yann Gueguen, Hiroyuki Muto, Atsunori Matsuda, et al.. Indentationinduced stress distribution and pressure effect on the resistivity of YSZ. Solid State Ionics, 2016, 286, pp.96-101. 10.1016/j.ssi.2015.12.026 . hal-01275556

HAL Id: hal-01275556

https://hal-univ-rennes1.archives-ouvertes.fr/hal-01275556

Submitted on 3 May 2016

HAL is a multi-disciplinary open access archive for the deposit and dissemination of scientific research documents, whether they are published or not. The documents may come from teaching and research institutions in France or abroad, or from public or private research centers.
L'archive ouverte pluridisciplinaire HAL, est destinée au dépôt et à la diffusion de documents scientifiques de niveau recherche, publiés ou non, émanant des établissements d'enseignement et de recherche français ou étrangers, des laboratoires publics ou privés. 


\section{Indentation-induced stress distribution and}

\section{pressure effect on the resistivity of YSZ}

Yusuke Daiko ${ }^{*}, a$, Eri Takahashi ${ }^{b}$, Yann Gueguen ${ }^{c}$, Hiroyuki Muto $^{d}$, Atsunori Matsuda ${ }^{d}$, Tetsuo Yazawa $^{b}$, Tanguy Rouxel ${ }^{c}$, Yuji Iwamoto ${ }^{a}$

${ }^{a}$ Department of Frontier Materials, Nagoya Institute of Technology, Gokiso-cho, Showa-ku, Nagoya, Aichi 466-8555, Japan

${ }^{b}$ Department of Materials Science and Chemistry, University of Hyogo, 2167 Shosha, Himeji, Hyogo 671-2280, Japan

${ }^{c}$ Mechanics and Glasses Department, IPR, UMR -CNRS 6251, Université de Rennes 1, Campus de Beaulieu, Rennes Cedex, 35042, France

${ }^{d}$ Department of Electrical and Electronic Information Engineering, Toyohashi University of Technology, 1-1 Hibarigaoka, Tempaku-cho, Toyohashi, Aichi 441-8580, Japan

\section{*Corresponding Author}

E-mail: daiko.yusuke@nitech.ac.jp 


\section{ABSTRACT}

Ionic conductivities measured under GPa-order high pressure provide various information about ion hopping mechanisms such as the activation volume $(\Delta V)$. Traditionally, anvil cells have been used for high-pressure measurements. We previously reported a new method for high-pressure impedance measurements, up to a few GPa, employing an indentation-induced local stress field. In this method, both mechanical and electrical (Young's modulus and high pressure impedance) properties can be obtained simultaneously. However, in this method, high pressures are induced only around the tip of the indenter, and such stress distribution should be considered for the estimation of $\Delta V$ accurately. In the present study, employing a finite element method (FEM) calculation, the stress distribution around the tip of the indenter, and effects of such GPa-order high pressures on the $\mathrm{O}^{2-}$ ion conduction are shown.

Keywords:

Indentation, Activation volume, Fuel cell, $\mathrm{Y}_{2} \mathrm{O}_{3}$-doped zirconia, Hertz theory 


\section{INTRODUCTION}

Electrochemical analysis of conducting and dielectric materials under high pressures has received considerable attention in view of various interesting properties such as crystallographic phase transition, shifts of temperatures (Curie point/superconducting transition) and changes in phonon modes [1-9]. For ionic conductors, conductivity, $\sigma$, is expressed as

$$
\sigma=\sigma_{0} \exp \{-(\Delta E+p \Delta V) / R T\}
$$

where $\sigma_{0}$ is a pre-exponential factor $[\mathrm{S} / \mathrm{cm}], \Delta E$ is the activation energy $[\mathrm{J} / \mathrm{mol}], p$ is the pressure $[\mathrm{Pa}], \Delta V$ is the activation volume $\left[\mathrm{cm}^{3} / \mathrm{mol}\right], R$ is the gas constant $[\mathrm{J} / \mathrm{mol} \cdot \mathrm{k}]$, and $T$ is the absolute temperature [k]. The respective derivative forms of $\Delta E$ and $\Delta V$ are

$$
\begin{aligned}
& \Delta E=-R T\left\{d(\ln \sigma) / d\left(T^{-1}\right)\right\}_{p}, \\
& \Delta V=-R T\{d(\ln \sigma) / d p\}_{T} .
\end{aligned}
$$

According to the temperature dependence of conductivity, at a constant pressure (e.g., 0.1 MPa of ambient pressure), $\Delta E$ can be obtained from Eq. (2). The $\Delta E$ is correlated with the energy barrier for ion hopping from a site to an adjacent site. Similarly, from the pressure dependence of conductivity at a constant temperature, $\Delta V$ can be obtained. $\Delta V$ is identified with local relaxation that accompanies the opening up of sites to admit incoming ions [1016]. A solid electrolyte of $\alpha-\mathrm{AgI}$ that readily conducts $\mathrm{Ag}^{+}$ions has a relatively small value of $\Delta V\left(\sim 0.9 \mathrm{~cm}^{3} / \mathrm{mol}\right)[12]$, whereas the typical ionic crystal $\mathrm{KCl}$ poorly conducts $\mathrm{K}^{+}$ions and has a reported $\Delta V$ of $\sim 8.0 \mathrm{~cm}^{3} / \mathrm{mol}[10]$.

Essentially, $\Delta E$ has only positive values, while $\Delta V$ has both positive and negative values. For example, $\Delta V$ for the rate constant $k$ of ammonia synthesis (Haber-Bosch process) is a negative value, suggesting the rate for ammonia synthesis increases with increasing pressure. Additionally, $\Delta V$ for electron including small polaron conductions are usually a 
negative value [17], and electron conductivity increases with increasing pressure owing to the overlap of wave functions. It has been reported that some ionic conductors such as $\mathrm{Li}^{+}$ionsubstituted $\beta-\mathrm{Al}_{2} \mathrm{O}_{3}$ have negative $\Delta V$ values, which correspond to an increase in conductivity with increasing pressure [18]. Evaluations of both $\Delta E$ and $\Delta V$ are thus important to understand the ion conduction mechanism in detail and also to screen a new type of electrolyte. However, high pressures of GPa order are usually indispensable for $\Delta V$ analysis of solid electrolyte, and high-pressure apparatuses such as diamond anvil cells are necessary for measurement $[19,20]$. Although the importance of $\Delta V$ measurements has been suggested in some literatures [10-16], few papers have reported experimental data for $\Delta V$, likely because of the difficulties and limitations associated with conventional high-pressure methods including the calibration of pressure, sample preparation (involving small sample sizes of $\sim 0.001 \mathrm{~cm}^{3}$ ) and temperature increase up to a few hundred ${ }^{\circ} \mathrm{C}$. In addition, measurements are often performed under a fixed atmosphere, which does not allow evaluation of impedance under various atmospheres (e.g., it is difficult to switch the measurement condition from an oxygen to hydrogen (fuel cell) atmosphere in the case for utilizing a diamond anvil cell).

We previously reported a new GPa-order high-pressure impedance measurement based on an indentation technique [21]. Indentation techniques have been widely used for the analysis of mechanical properties such as the elastic modulus, hardness and viscosity [22-26]. An important point about this method is that the indentation-induced local stress reaches values scaling with hardness, i.e. of a few GPa, and we have tried to utilize this local stress field induced around the tip of the indenter for high-pressure impedance measurement. The value of $\Delta V$ for $10 \mathrm{~mol} \% \mathrm{Y}_{2} \mathrm{O}_{3}$-doped zirconia (YSZ) was estimated to be around 3.9 $\mathrm{cm}^{3} / \mathrm{mol}[21] . \Delta V$ increases with increasing temperature, and a similar behavior was reported 
for typical electrolytes $[11,12,27]$, as well as for creep viscosity measurements in glasses and polymers $[28,29]$.

Employing the above method, $\Delta V$ can be easily and rapidly obtained without any pressure mediums or pressure calibrations. In this indentation method, however, GPa-order high pressure is induced only around the tip of the indenter. Thus, the stress distribution should be considered in order to estimate the effect of high pressure for $\mathrm{O}^{2-}$ ion conduction accurately. As such, no physical correlation can be drawn between $\Delta V$ values obtained under uniform stress (e.g., using an anvil cell) and those obtained under local stress (indentation) conditions.

In this study, the stress distribution around the tip of an indenter and its effect on the conduction for $\mathrm{O}^{2-}$ ion hopping were estimated using a finite element method (FEM) considering both linear elasticity for the mechanical behavior and Eq. (1) for the conductivity, and the simulation results were compared with experimental data. $\Delta V$ of YSZ is discussed in relation to the stress distribution.

\section{Experimental}

Yttria-doped zirconia (10 mol\% $\mathrm{Y}_{2} \mathrm{O}_{3}$, TOSOH Co., Japan) (10YSZ) was used as the test material. 10YSZ powder $(0.8 \mathrm{~g})$ was pelletized $(13 \mathrm{~mm}$ in diameter $)$ at $25 \mathrm{kN}$ and room temperature, and subsequently sintered at $1500^{\circ} \mathrm{C}$ for $1 \mathrm{~h}$. The obtained sample was mirrorpolished using a diamond slurry $(0.25-\mu \mathrm{m}$ diamond, IMT Co., Ltd., Japan). The indentation measurements were performed using a hand-made indentation apparatus [21]. A spherical Inconel625 indenter was used in the case for the measurement of high-pressure impedance. As shown in Fig. 1, the Inconel indenter plays the role of a collecting electrode simultaneously. The curvature radius of the Inconel indenter was $0.5 \mathrm{~mm}$. A gold ring electrode was sputtered on the 10YSZ. The electrical resistance for $\mathrm{O}^{2-}$ ion conduction 
between the ring electrode and indenter was measured using an LCR meter (ZM2376, NF Corporation, Japan) at frequencies ranging from $10 \mathrm{kHz}$ to $20 \mathrm{~Hz}$ and $1 \mathrm{~V}$ under a nitrogen gas atmosphere that prevented oxidation of the apparatus.

Finite element simulation software (COMSOL Multiphysics ${ }^{\circledR}$ ver. 5.1 with AC/DC and structural mechanics modules) was used for the simulation of the stress distribution and of the resistance according to Eq. (1). Parameters for the simulation are summarized in Table 1. The activation energy for $10 \mathrm{YSZ}$ was reported to be $\approx 100 \mathrm{~kJ} / \mathrm{mol}$ and $80 \mathrm{~kJ} / \mathrm{mol}$ at temperatures around $500^{\circ} \mathrm{C}$ and above $800^{\circ} \mathrm{C}$, and $100 \mathrm{~kJ} / \mathrm{mol}$ was substituted into the $\Delta E$ of Eq. (1) for the FEM calculation [30-33]. An axially symmetric two-dimensional model was used; the sample geometry is shown in Fig. 2. All sizes of the sample, ring electrode, and indenter were exactly the same as for the experimental condition of indentation. The indenter and YSZ constituted a contact pair, and boundary conditions of contact and continuity were used for structural mechanics and AC/DC modules, respectively. A point load from 1 to $25 \mathrm{~N}$ was applied at $\mathrm{P}_{2}$ in Fig. 2. The mesh used for the finite element analysis is shown in Fig. 3. Triangle and square elements were used in order to reduce the calculation time effectively; the numbers of element were 10035 and 1736 , respectively.

\section{Results and discussion}

\subsection{Hertz's elastic theory for YSZ}

Indentation techniques, measuring the relationship between the load $(P)$ and penetration depth $(h)$, have been widely used for the analysis of mechanical properties, and e.g. the elastic modulus, yield strength, hardness as well as time-dependent-viscoelastic parameters can be obtained [22-26,34]. We have used a spherical indenter in order to vary the contact pressure easily. Note that the contact pressure changes by changing the indentation load only in the elastic deformation regime when a spherical indenter is used, since the 
contact pressure becomes load independent when a permanent deformation occurs. The indentation load was stepwise increased from 0 to $25 \mathrm{~N}$, and the load was kept at constant values $(5,10,15,20$ and $25 \mathrm{~N})$ for $100 \mathrm{~s}$, and impedance measurement was performed during the constant loads using an LCR meter.

The relationship between the load $(P)[\mathrm{N}]$ and penetration depth $(h)[\mu \mathrm{m}]$ at $500^{\circ} \mathrm{C}$ is shown in Fig. 4a. The dot-line represents the result of fitting based on the Hertz's elastic model. It is clear that the line is well-fitted on the experimental $P$ - $h$ curve:

$$
\begin{aligned}
& P=4 / 3 E^{*} r^{1 / 2} h^{3 / 2} \\
& E^{*}=\left\{\left(1-v_{\mathrm{s}}^{2}\right) / E_{\mathrm{s}}+\left(1-v_{\mathrm{i}}^{2}\right) / E_{\mathrm{i}}\right\}^{-1}
\end{aligned}
$$

where $r$ is the curvature radius of the spherical indenter $(r=0.5 \mathrm{~mm}), E^{*}$ is the effective elastic modulus, $E$ and $v$ are the Young's modulus and Poisson's ratio, and the subscripts $\mathrm{s}$ and $\mathrm{i}$ refer to the sample and indenter, respectively. Also, the loading and unloading curves are exactly overlapped using the spherical indenter at $500^{\circ} \mathrm{C}$, suggesting a full elastic deformation of the 10YSZ under the measurement condition. Thus, the indentation behavior was analyzed based on the Hertz's elastic model. No cracks or other damage were seen in either the 10YSZ or the indenter after the test.

According to the data, the Young's modulus and Poisson's ratio of Inconel625 are $\approx 180 \mathrm{GPa}$ and 0.3 at $500^{\circ} \mathrm{C}[35,36]$. The Poisson's ratio of $10 \mathrm{YSZ}$ was reported to be $\approx 0.3$ [37]. By assuming the value of the Poisson's ratio $v=0.3$ for 10YSZ, the Young's modulus of $10 \mathrm{YSZ}$ was estimated to be $150 \mathrm{GPa}$ at $500^{\circ} \mathrm{C}$ from the equations (4) and (5). Similar values have also been reported [38]. One big advantage compared with the traditional high-pressure test (e.g. diamond anvil cell) is that the mechanical and electrical properties can be simultaneously estimated in our indentation method.

Here it should be mentioned that the yield strength of Inconel625 is depending on some treatments including the aging temperature and time, and the value was reported to be 
less than $1 \mathrm{GPa}$ at $500^{\circ} \mathrm{C}[35,36]$. In some cases, the $E^{*}$ obtained from $P$ - $h$ curve (Fig. 4a) changed slightly after using the same Inconel indenter several times. A mechanical damage for the Inconel indenter may occur. The indenter was thus changed frequently. Recently, a harder material with a good conductivity such as boron-doped diamond has also been used for indentation/conductivity analysis [39].

\subsection{Stress distribution and resistance}

In our indentation method, the GPa order high pressure is induced only around the tip of indenter. The conductivity was previously calculated using the resistance, the contact area of the indenter, and the distance between the indenter and ring-electrode [21]. The activation volumes of $\approx 3.9 \mathrm{~cm}^{3} / \mathrm{mol}$ were obtained from the slope of conductivity $(\log \sigma)$ vs pressure. In this calculation, however, we ignored the stress distribution for the calculation of conductivity, and such stress distribution should be considered for the estimation of $\Delta V$ accurately. In the present study, we used a finite element method (FEM) to clarify the effect of the local-induced high pressure for ion conduction. Fig. $4 \mathrm{~b}$ shows the $P$ - $h$ curve obtained using the FEM calculation. The same $P$ - $h$ curve for Hertz's elastic model in Fig. $4 \mathrm{a}$ is also replotted. It is clear that these three $P$ - $h$ curves are in good agreement to each other.

Fig. 5a shows the $2 \mathrm{D}$ view of the pressure at Gauss point calculated by the FEM $(P=$ $25 \mathrm{~N}$ ), and the relationship between the distance $(x)$ from the tip of indenter and the pressure on the YSZ surface ( $y=0$ in Fig. $5 \mathrm{a})$ is shown in Fig. $5 \mathrm{~b}$ (1D view). Note that approximately $5 \mathrm{GPa}$ is induced at the contact region between Inconel and YSZ. The pressure decreases drastically with increasing the distance $x$, and the high pressure region disappears over $x=$ $0.05 \mathrm{~mm}$.

We calculated the maximum pressure (Hertz's pressure, $p[\mathrm{~Pa}]$ ) from the penetration depth $h$ as follows: 


$$
\begin{aligned}
& a_{\mathrm{c}}=(r \cdot h)^{1 / 2} \\
& p=3 P / 2 \pi a_{\mathrm{c}}^{2}
\end{aligned}
$$

where $a_{\mathrm{c}}$ is the contact radius of the indenter $\left[\mathrm{m}^{2}\right]$. Relationships between the indentation load and contact pressure, calculated using the experimentally measured penetration depth (Eq. (6) and (7)) or FEM calculation, are shown in Fig. 6. It is evident that the FEM calculation is in very good agreement with experimental results, suggesting a suitable mesh and parameters of FEM calculation.

The obtained pressure at the Gauss point of each node was substituted into the $p$ of Eq. (1), and conductivity of 10YSZ was defined as a function of the pressure, followed by the FEM calculation of the current density $\left[\mathrm{A} / \mathrm{m}^{2}\right]$. For the FEM calculation, $1 \mathrm{~V}$ was applied between the indenter and ring electrodes. The current $[\mathrm{A}]$ was obtained by the integration of the current density with the area of ring-electrode. Here, $\sigma_{0}$ and $\Delta V$ were varied, and we compared the resistivities between experimental (LCR) and FEM calculation for various $\sigma_{0}$ and $\Delta V$.

Typical Cole-Cole plot is shown in Fig. 7. The resistance at a resonant frequency shown as the arrow (the first semicircle) was adopted. Since our sample was not single crystal, the resistance is considered to be included both grain and grain boundary resistances. In this study, we focused only bulk (grain and grain boundary) resistance. Note the bulk resistance decreases, while the estimated contact area increases with increasing the load from 5 to $25 \mathrm{~N}$. As shown in Fig. 1, the Inconel indenter also plays the role of a collecting electrode. Since the hopping of $\mathrm{O}^{2-}$ ions occurs between the indenter and ring electrodes, such a small high-pressure region should affects on the resistance for $\mathrm{O}^{2-}$ conduction.

Typical results of the resistance of the experimental data and FEM calculation are shown in Fig. 8. The $\Delta V$ value affects significantly on resistance at higher load. The 
differences $(\delta)$ of resistances between experimental and FEM calculation were estimated as follow:

$$
\delta=\sum\left(R_{\text {experimental }}-R_{\mathrm{FEM}}\right)^{2}
$$

where $R_{\text {experimental }}$ and $R_{\text {FEM }}$ are resistances obtained from experiment and FEM calculation, respectively. In the case of $\Delta V=0 \mathrm{~cm}^{3} / \mathrm{mol}$, the FEM calculation is in agreement with experimental data in lower loads, whereas a deviation is clearly seen over $15 \mathrm{~N}$ (corresponding to that over $\sim 4 \mathrm{GPa}$ from Fig. 6). A smaller $\delta$ value was obtained for $\Delta V=3.5$ $\mathrm{cm}^{3} / \mathrm{mol}$ as compared with the case for $\Delta V=2.0 \mathrm{~cm}^{3} / \mathrm{mol}$, suggesting that the $\Delta V$ of $10 \mathrm{YSZ}$ is around $3.5 \mathrm{~cm}^{3} / \mathrm{mol}$ at $500^{\circ} \mathrm{C}$.

In any cases for $\Delta V$ from 0 to $3.5 \mathrm{~cm}^{3} / \mathrm{mol}$, the $\sigma_{0}$ was estimated to be around $2000 \sim$ $2300 \mathrm{~S} / \mathrm{cm}$. The $\sigma_{0}$ is composed of several terms including the average jump distance squared, the density of charge carriers and the attempt frequency of the jumping atom etc. The Meyer-Neldel (MN) rule has been widely studied since its discovery in 1937. The MN rule can be applied for various activated hopping systems including electron/hole conduction of semiconductors, ionic conduction as well as thermally activated hopping and so on [40]. According to the NM rule, a linear relationship can be seen between the activation energy and $\log \sigma_{0}$, and various materials obey the NM rule [40]. The relationship between the $\log \sigma_{0}$ and $\Delta E$ for YSZ measured at various temperatures and compositions (varied the amount of $\mathrm{Y}_{2} \mathrm{O}_{3}$ ) is plotted in Fig. 9. Note that the FEM calculation result $\left(\sigma_{0}=2300 \mathrm{~S} / \mathrm{cm}\right.$ at $\Delta E=100$ $\mathrm{kJ} / \mathrm{mol}$ ) is in very good agreement with the NM correlation for YSZ, and thus we conclude the $\sigma_{0}$ calculated is also reasonable.

A estimation of the activation volume, $\Delta V$, can be obtained easily and rapidly by just fitting the experimentally obtained resistance data based on the Eq. (1), once the stress distribution around the tip of the indenter is accounted for using FEM for instance. It should be mentioned, however, the experimental error for the resistance becomes notable in lower 
load (see Fig. 8), maybe due to very small value of the contact area. As shown in Fig. 6, the pressure increases drastically from 0 up to 5 N. In Fig. 10, the FEM calculation results for the $\Delta V=2.0$ and $3.5 \mathrm{~cm}^{3} / \mathrm{mol}$ in Fig. 8 are replotted for comparison. Note the effect on the local stress around the tip of indenter become more significant below $10 \mathrm{~N}$. Our experimental and calculation results suggest that a precise indentation measurement for resistance in the region 0 to $10 \mathrm{~N}$ of load is necessary in order to evaluate the $\Delta V$ precisely. Further improvement for the indentation measurement, especially about the indentation test under lower load-region is in progress. Also, the comparison of $\Delta V$ obtained under uniform stress (e.g., using an anvil cell) and those obtained under local stress (indentation) conditions is under studying.

\section{Conclusion}

The pressure effect on the $\mathrm{O}^{2-}$ conduction of YSZ was measured by using an indentation apparatus, and experimentally obtained resistance is discussed in relation with the FEM calculation. The $P$ - $h$ profile curve was obtained with a good reproducibility and accuracy, and profile data was well fitted by the Hertz's theoretical values. The indentation induced high-pressure stress field can be applied for the estimation of $\Delta V$, and the $\Delta V$ of 3.5 $\mathrm{cm}^{3} / \mathrm{mol}$ was obtained by considering the stress distribution around the tip of indenter using the finite element method. Compared with conventional techniques for the calculation of $\Delta V$, the apparatus we developed is very simple, performs rapid analysis, and mechanical and electrical properties are obtained simultaneously.

\section{Acknowledgment}

This work was financially supported by the Ministry of Education, Culture, Sports, Science and Technology (Japan) (No. 23686095, No. 15H04124) and by Toyota Physical and Chemical Research Institute Scholars. 


\section{REFERENCES}

[1] R.K. Chan, D.W. Davidson, E. Whalley, J. Chem. Phys. 43 (1965) 2376.

[2] G.A. Samara, Phys. Rev. B 27 (1983) 3494.

[3] I.N. Goncharenko, I. Mirebeau, Phys. Rev. Lett. 80 (1998) 1082.

[4] H. Karzel, W. Potzel, M. Köfferlein, W. Schiessl, M. Steiner, U. Hiller, G.M. Kalvius, D.W. Mitchell, T.P. Das, P. Blaha, K. Schwarz, M.P. Pasternak, Phys. Rev. B 53 (1996) 11425.

[5] S. Sadewasser, J.S. Schilling, A.P. Paulikas, B.W. Veal, Phys. Rev. B 61 (2000) 741.

[6] F. Iguchi, S. Onodera, N. Sata, H. Yugami, Solid State Ionics 225 (2012) 99.

[7] D.A. Boysen, S.M. Haile, H. Liu, R.A. Secco, Chem. Mater. 15 (2003) 727.

[8] H. Takahashi, K. Igawa, K. Arii, Y. Kamihara, M. Hirano, H. Hosono, Nature 453 (2008) 376.

[9] G.A. Samara, Phys. Rev. 151 (1966) 378.

[10] D.N. Yoon, D. Lazarus, Phys. Rev. B 5 (1972) 4935.

[11] P.C. Allen, D. Lazarus, Phys. Rev. B 17 (1978) 1913.

[12] B.-E. Mellander, Phys. Rev. B 26 (1982) 5886.

[13] A. Bunde, M.D. Ingram, S. Russ, Phys. Chem. Chem. Phys. 6 (2004) 3663.

[14] G.A. Samara, Solid State Phys. 38 (1984) 1.

[15] R. Hinrichs, G. Tomandl, J.A.H. da Jornada, Solid State Ionics 77 (1995) 257.

[16] Q. Chen, A. Braun, S. Yoon, N. Bagdassarov, T. Graule, J. Eur. Ceram. Soc. 31 (2011) 2657.

[17] A. Goddat, J. Peyronneau, J.P. Poirier, Phys. Chem. Miner. 27 (1999) 81.

[18] R.H. Radzilowski, T. Kummer, J. Electrochem. Soc. 118 (1971) 714.

[19] A. Hao, C. Gao, M. Li, C. He, X. Huang, G. Zou, Y. Tian, Y. Ma, J. Appl. Phys. 101 (2007) 053701.

[20] S. Matsuzaki, Synthetic Metals 61 (1993) 207.

[21] Y. Daiko, E. Takahashi, N. Hakiri, H. Muto, A. Matsuda, T. Rouxel, J.-C. Sangleboeuf, A. Mineshige, T. Yazawa, Solid State Ionics 254 (2014) 6.

[22] G.M. Pharr, Mater. Sci. Eng. A 253 (1998) 151.

[23] S. Yoshida, J.-C. Sangleboeuf, T. Rouxel, J. Mater. Res. 20(12) (2005) 3404.

[24] B.R. Lawn, A.G. Evans, D.B. Marshall, J. Am. Ceram. Soc. 63 (1980) 574.

[25] J.-J. Kim, Y. Choi, S. Suresh, A.S. Argon, Science 295 (2002) 654. 
[26] R. Saha, W.D. Nix, Acta Mater. 50 (2002) 23.

[27] M.D. Ingram, C. T. Imrie, I. Konidakis, S. Voss, Phys. Chem. Chem. Phys. 6 (2004) 3659 .

[28] T. Rouxel, M. Huger and J.L. Besson, J. Mat. Sci. 27 (1992) 279.

[29] J.C. Cavrot, J. Haussy, J.M. Lefebvre, B. Escaig, Mater. Sci. Eng. 36 (1978) 95.

[30] A. Pimenov, U. Ulrich, P. Lunkenheimer, A. Loidl, C.H. Rüscher, Soli State Ionic 109 (1998) 111.

[31] G. Chiodelli, A. Magistris, J. Mater. Sci. 23 (1998) 1159.

[32] M.J. Verkerk, B.J. Middelhuis, A.J. Burggraaf, Solid State Ionics 6 (1982) 159.

[33] S.P.S. Badwal, Solid State Ionics 52 (1992) 23.

[34] M. Sakai, S. Shimizu, J. Non-Cryst. Solids 282 (2002) 236.

[35] http://www.specialmetals.com/ (SPECIAL METALS, Inconel alloy 625 ResearchGate)

[36] http://www.jacquet.biz/JACQUET/USA/files/JCQusa-alloy-625.pdf (Alloy625datasheet)

[37] S. Sakaguchi, N. Murayama, Y. Kodama, F. Wakai, J. Mater. Sci. Lett. 10 (1991) 282.

[38] S. Giraud, J. Canel, J. Eur. Ceram. Soc. 28 (2008) 77.

[39] S. Ruffell, J.E. Bradby, J.S. Williams, O.L Warren, J. Mater. Res. 22 (2007) 578.

[40] A. Dalvi, N.P. Reddy, S.C. Agarwal, Solid State Comm. 152 (2012) 612.

[41] A. Pimenov, J. Ullrich, P. Lunkenheimer, A. Loidl, C.H. Rüscher, Solid State Ionics 109 (1998) 111.

[42] G. Chiodelli, A. Magistris, J. Mater. Sci. 23 (1988) 1159.

[43] M.J. Verkerk, B.J. Middelhuis, A.J. Burggraaf, Solid State Ionics 6 (1982) 159. 
Captions

\begin{tabular}{|c|c|}
\hline Parameter & Value \\
\hline $\begin{array}{l}\text { Curvature radius of the Inconel } \\
\text { indenter }\end{array}$ & $0.5 \mathrm{~mm}$ \\
\hline Young's modulus of YSZ & $190 \mathrm{GPa}$ \\
\hline Young's modulus of Inconel & $179 \mathrm{GPa}$ \\
\hline Poisson's ratio (Inconel, YSZ) & 0.3 \\
\hline Density of YSZ & $5.8 \mathrm{~g} / \mathrm{cm}^{3}$ \\
\hline Density of Inconel & $9.0 \mathrm{~g} / \mathrm{cm}^{3}$ \\
\hline Load & $1 \sim 25 \mathrm{~N}$ \\
\hline Conductivity of Inconel & $10^{5} \mathrm{~s} / \mathrm{m}$ \\
\hline$\Delta E$ & $100 \mathrm{~kJ} / \mathrm{mol}$ \\
\hline
\end{tabular}

Table 1. Parameters for FEM calculation. 


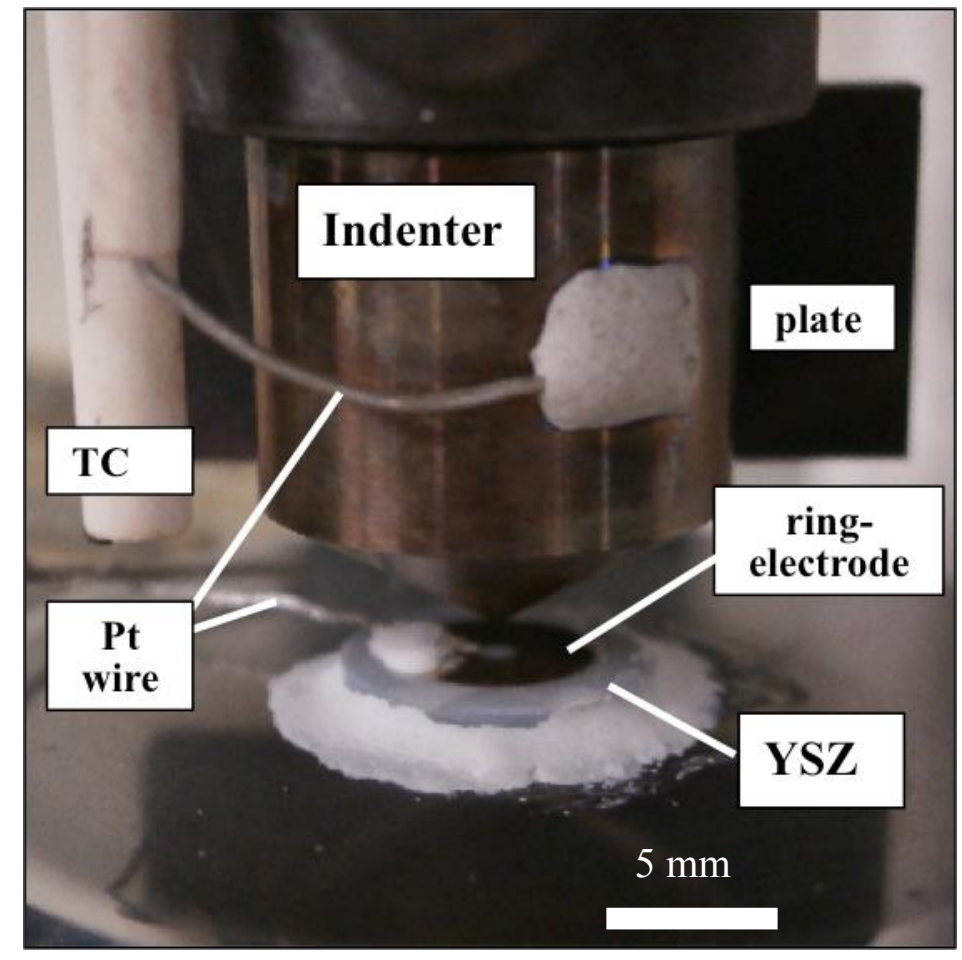

Figure 1. Photograph of the indenter and ring electrodes for the high-pressure impedance test (TC: thermocouple). 


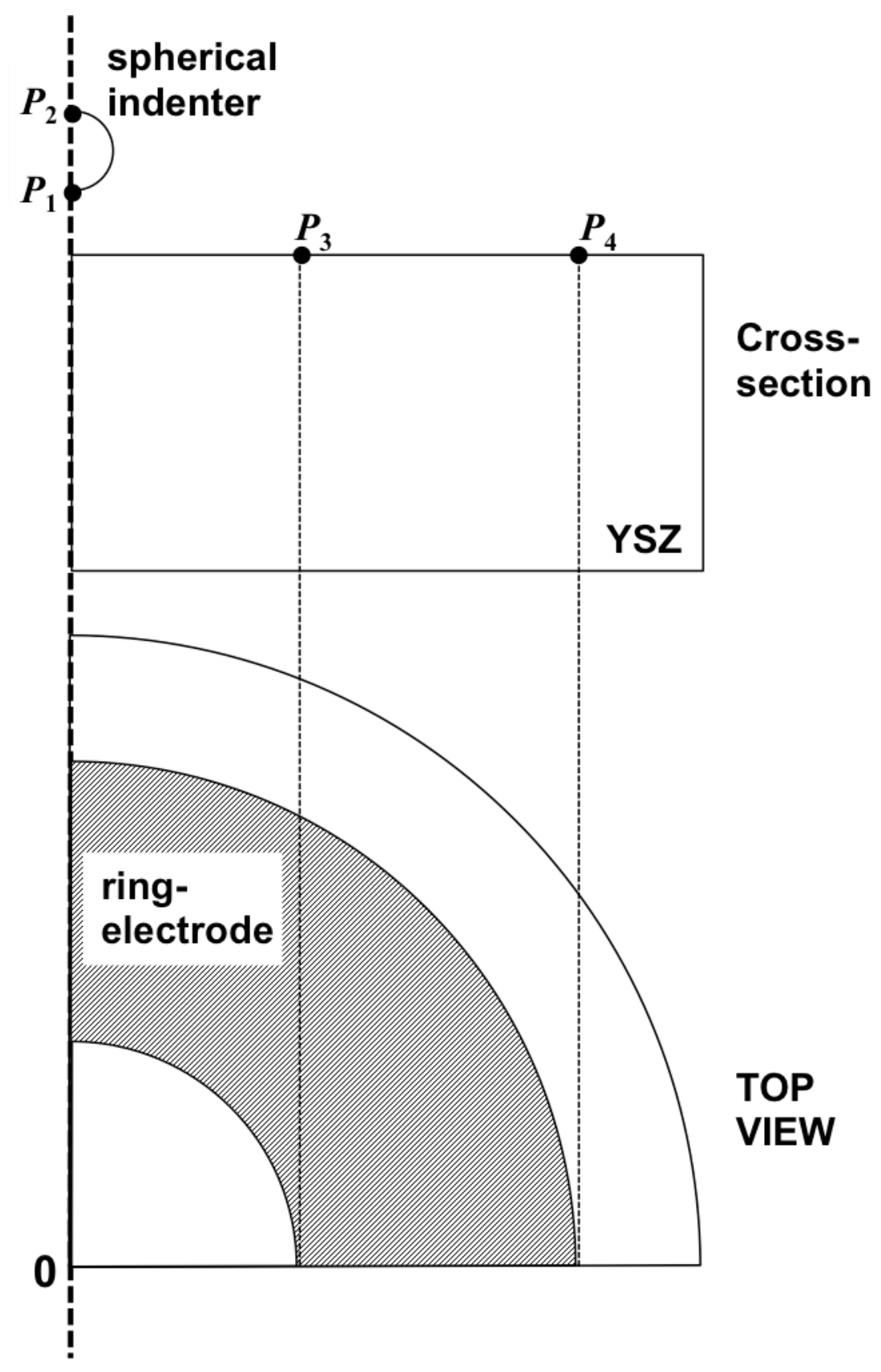

Figure 2. Cross-section and top views of the sample geometry for the FEM calculation. 


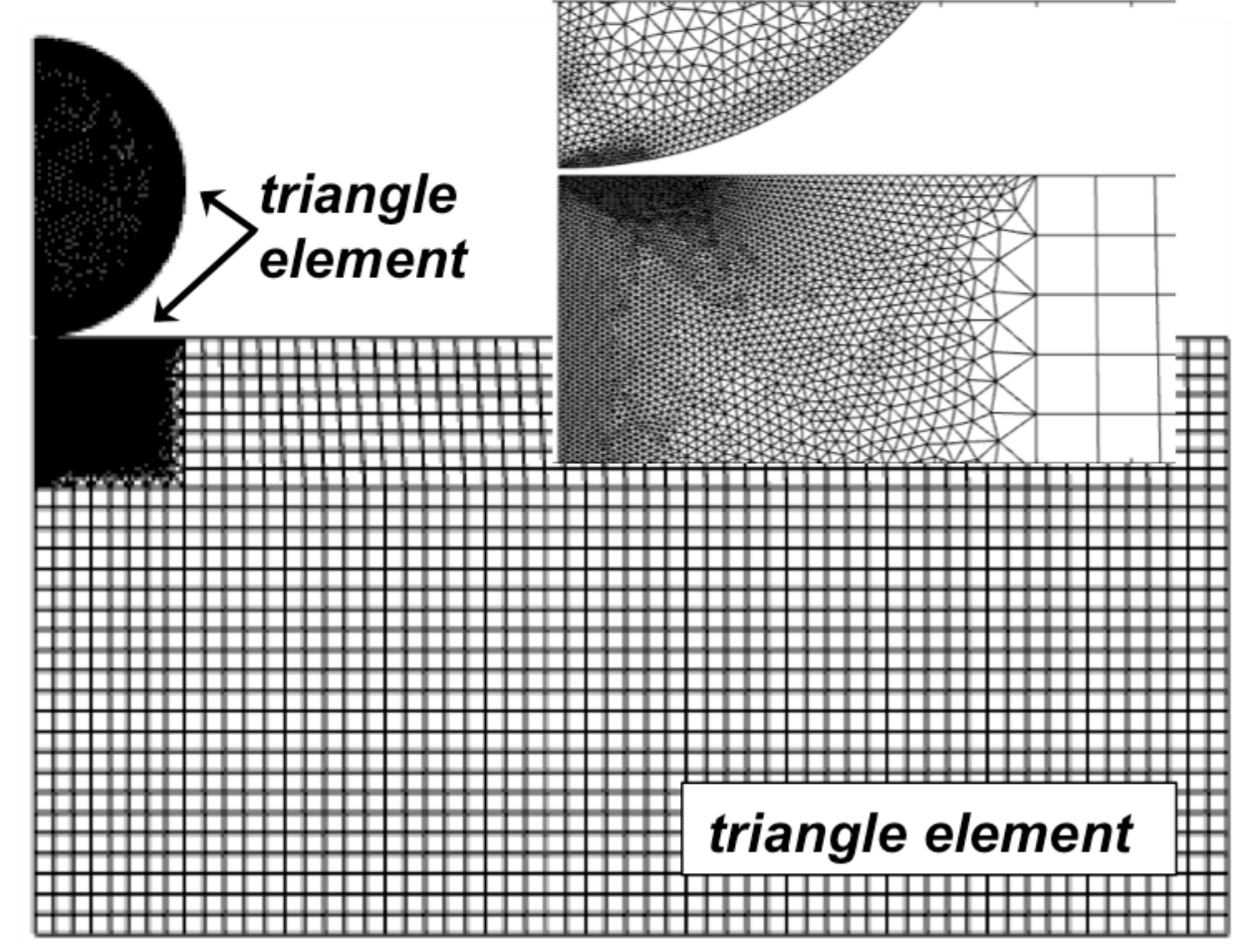

Figure 3. Mesh used for the finite element method. 

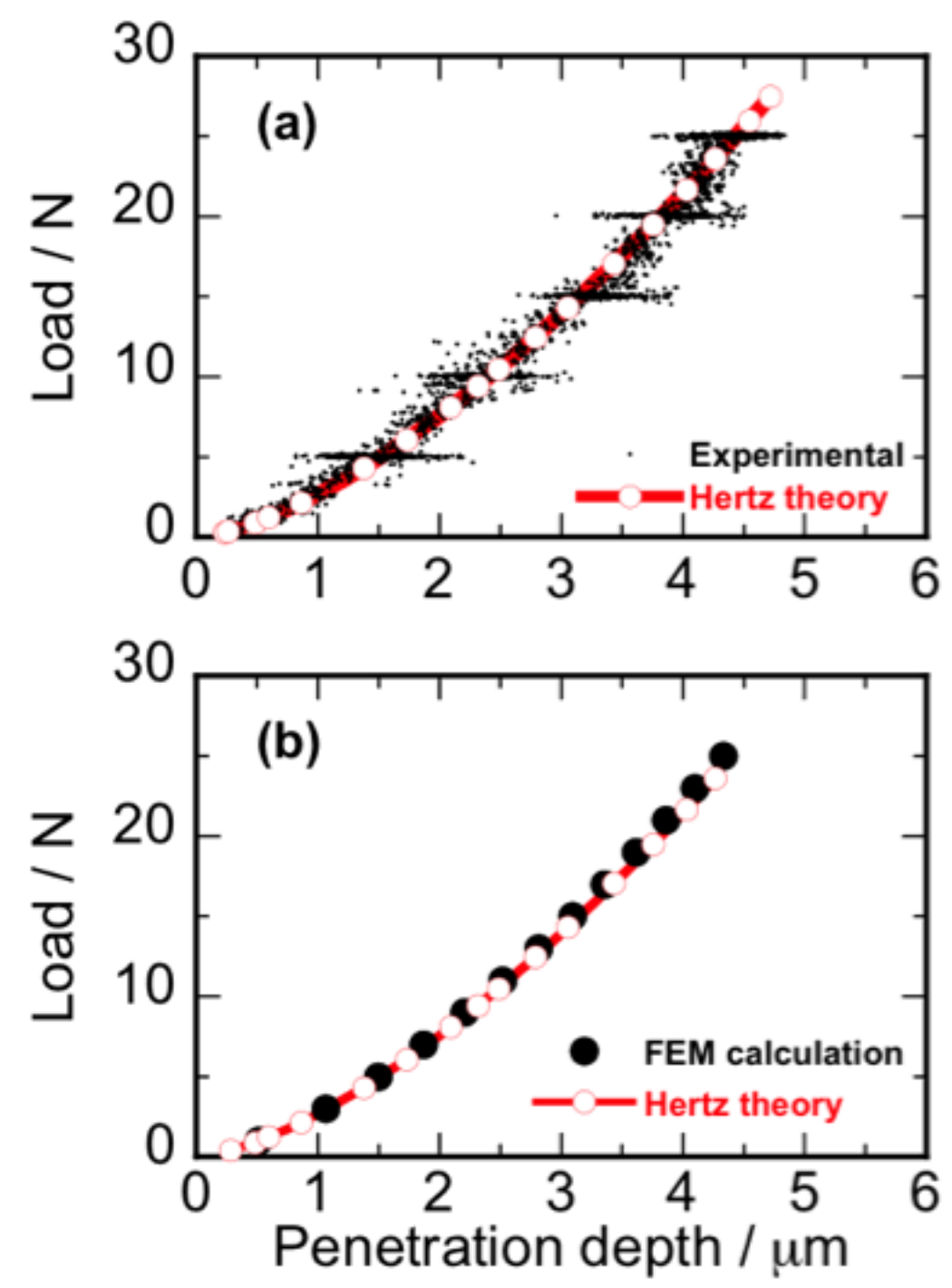

Figure 4. (a) $P-h$ curve for $Y S Z$ at $500^{\circ} \mathrm{C}$ measured using the spherical Inconel625 indenter, and (b) that obtained by FEM calculation. The red-curves represent the result of calculation based on the Hertz's elastic model. 

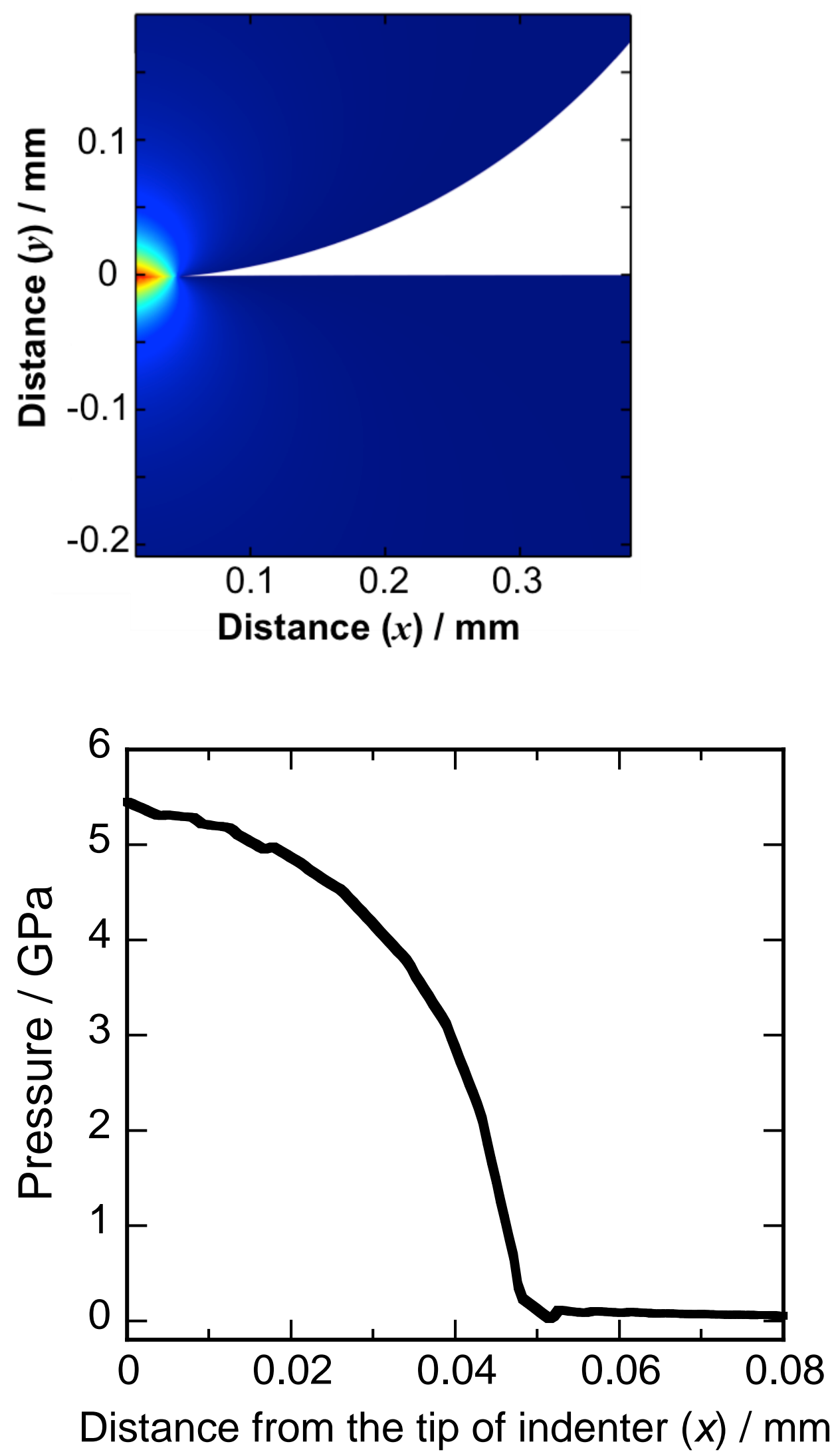

Figure 5. (a) $2 \mathrm{D}$ view of the pressure at Gauss point calculated by the FEM $(P=25 \mathrm{~N})$, and (b) the relationship between the distance $(x)$ from the tip of indenter and the pressure on the 10 YSZ surface ( $y=0$ in Fig. 5a). 


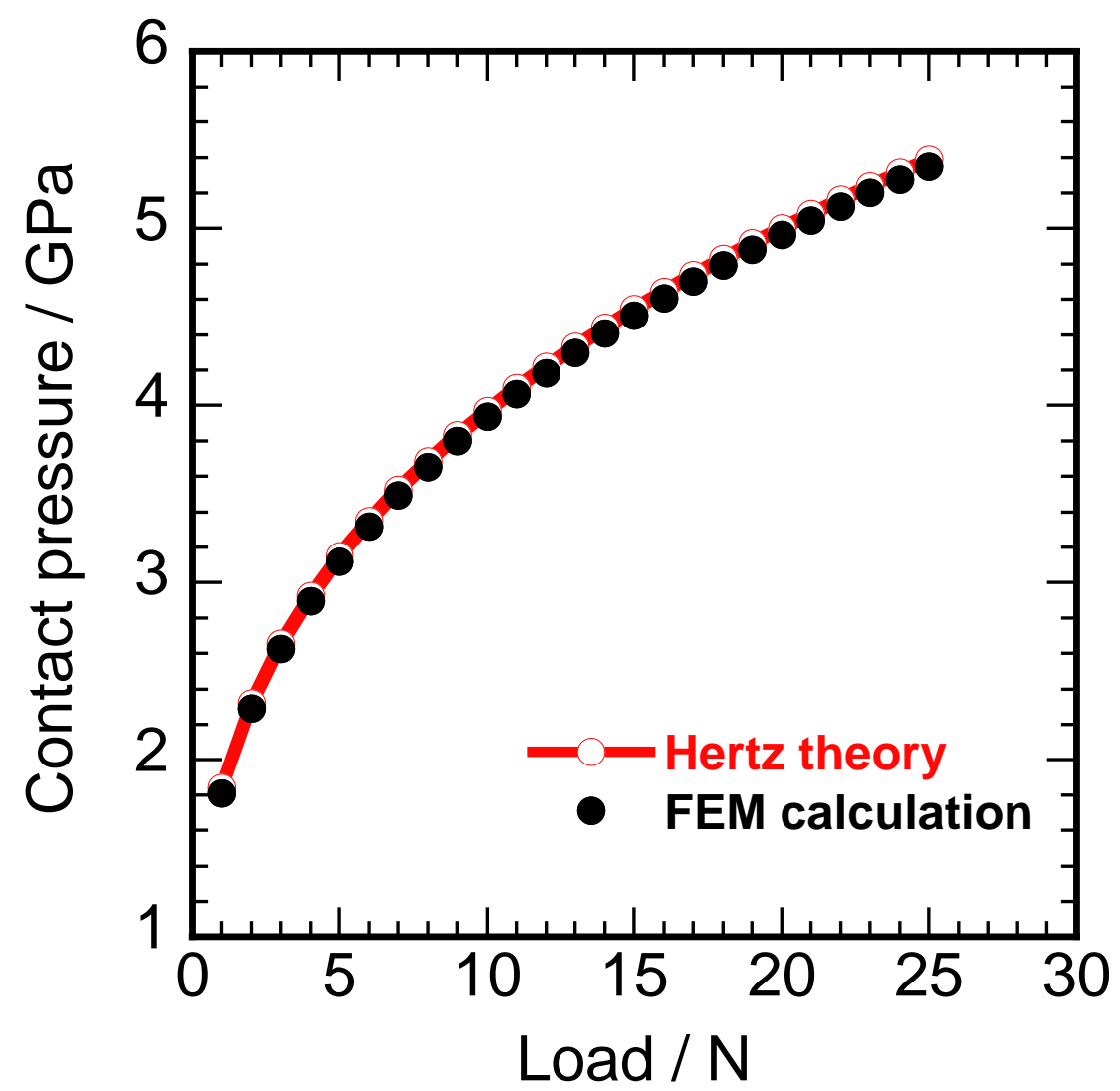

Figure 6. Relationships between the indentation load and contact pressure at $500^{\circ} \mathrm{C}$, calculated using the experimentally measured penetration depth (Eq. (6) and (7)) and FEM. 

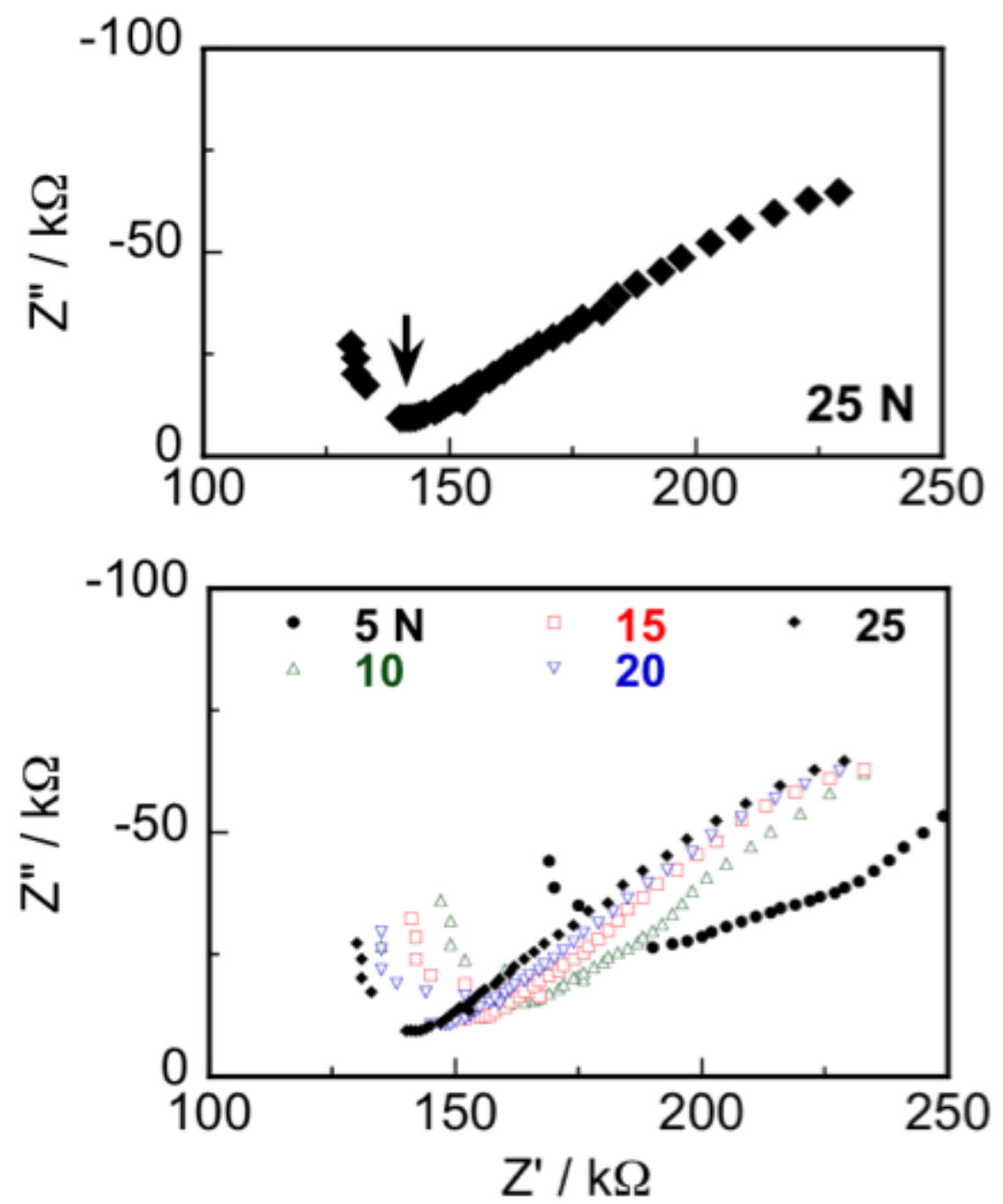

Figure 7. Cole-Cole plots of $10 \mathrm{YSZ}$ at $500{ }^{\circ} \mathrm{C}$ and $5 \mathrm{~N}$ for the ring electrode. The resistance shown by the arrow (the first semicircle) was used for the calculation of conductivity. 

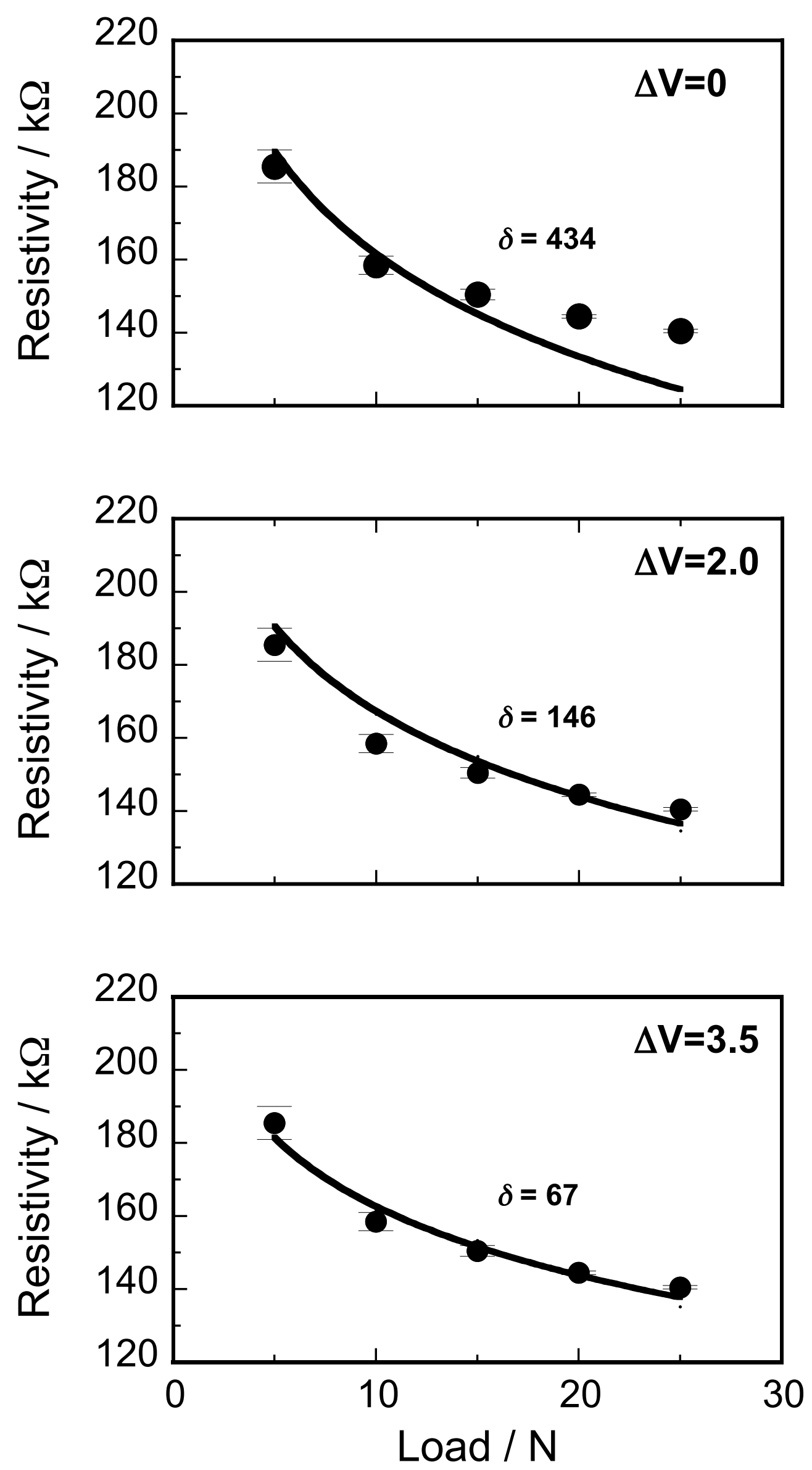
Figure 8. Comparison of the resistance between experimental data and FEM calculation at different $\Delta V$ from 5 to $25 \mathrm{~N}$. The symbol $(\bullet)$ and line show the results of experimental and FEM calculations, respectively. 


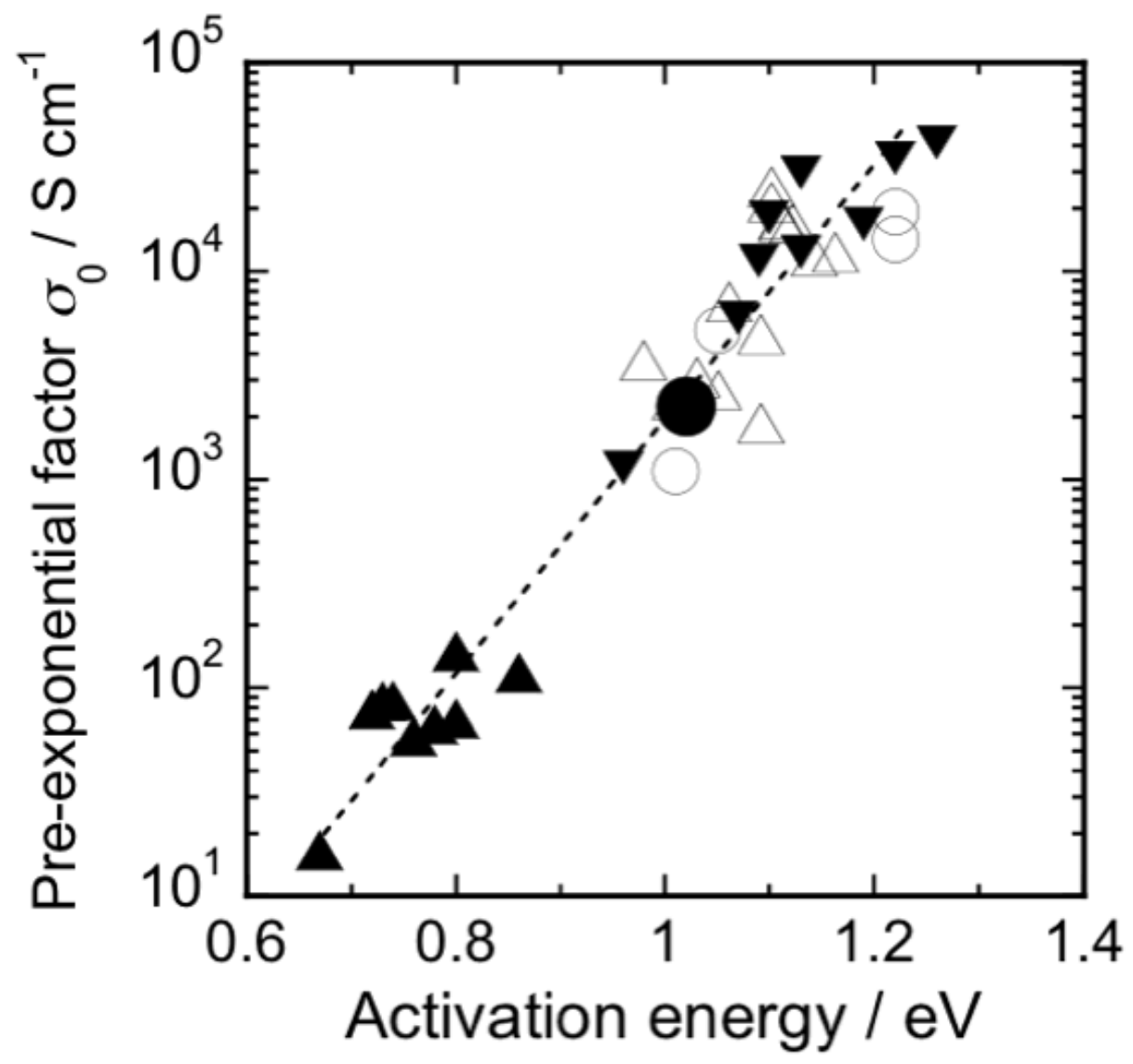

Figure 9. Relationship between the $\Delta E$ and $\log \sigma_{0}$ for YSZ measured at various temperatures and compositions (varied the amount of $\mathrm{Y}_{2} \mathrm{O}_{3}$ ); $\bullet$ : the FEM calculation result, $\Delta$ : ref[43], $\mathbf{\Delta}$ : ref [42] (High temperature), ०: ref[41], $\boldsymbol{\nabla}: \operatorname{ref}[42]$ (Low temperature). 


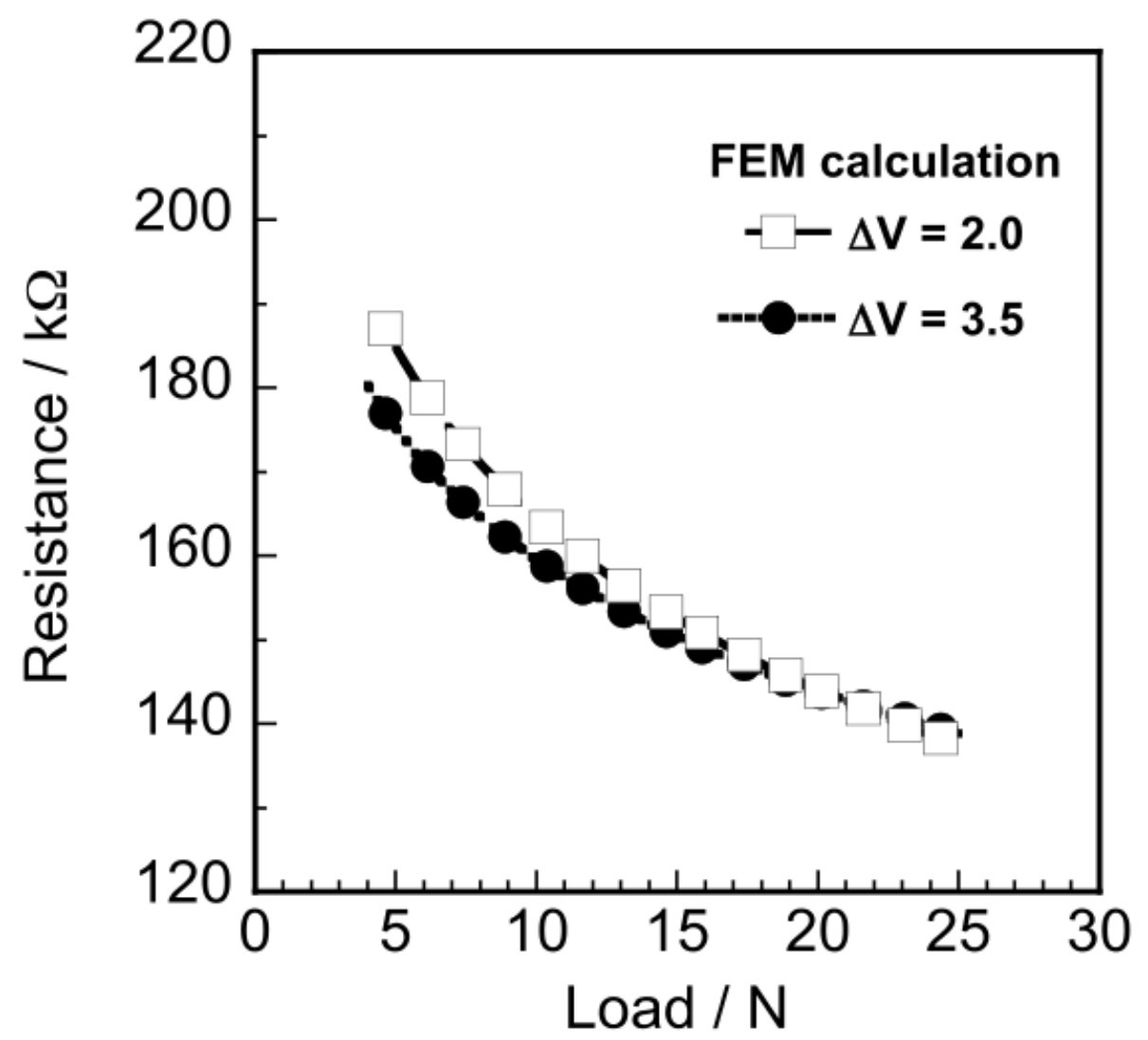

Figure 10. FEM calculation results for $\Delta V=2.0$ and 3.5 (re-plot the curves shown in Fig. 8) 